\title{
The status of Cantonese in the education policy of Hong Kong
}

Kwai Sang Lee and Wai Mun Leung*

* Correspondence: waimun@ied. edu.hk

Department of Chinese, The Hong Kong Institute of Education, Hong Kong

\begin{abstract}
After the handover of Hong Kong to China, a first-ever policy of "bi-literacy and tri-lingualism" was put forward by the Special Administrative Region Government. Under the trilingual policy, Cantonese, the most dominant local language, equally shares the official status with Putonghua and English only in name but not in spirit, as neither the promotion nor the funding approaches on Cantonese match its legal status. This paper reviews the status of Cantonese in Hong Kong under this policy with respect to the levels of government, education and curriculum, considers the consequences of neglecting Cantonese in the school curriculum, and discusses the importance of large-scale surveys for language policymaking.
\end{abstract}

Keywords: the status of Cantonese, "bi-literacy and tri-lingualism" policy, language survey, Cantonese language education

\section{Background}

The adjustment of the language policy is a common phenomenon in post-colonial societies. It always results in raising the status of the regional vernacular, but the language of the ex-colonist still maintains a very strong influence on certain domains. Taking Singapore as an example, English became the dominant language in the workplace and families, and the local dialects were suppressed. It led to the degrading of both English and Chinese proficiency levels according to scholars' evaluation (Goh 2009a, b). This interesting situation urges us to seriously consider the impact of the absence of mother tongue in education policy on the society. Hong Kong is a city with a similar language situation to Singapore, and it is worth evaluating the success of Hong Kong's language policy in education.

Cantonese is the most commonly spoken language in Hong Kong. In most of the British colonial era, the sole official language was English, and Chinese was made a coofficial language of Hong Kong only in as late as 1974. By "Chinese" it was understood to be Modern Standard Chinese as the written form and Cantonese as the spoken form in the context of Hong Kong, and there was no specific mention of the legal position of Cantonese. After Hong Kong's handover to China in 1997, the language policy of "bi-literacy and tri-lingualism" was conceived and implemented by the Government of the Hong Kong Special Administrative Region (hereafter SAR Government). "Bi-literacy" refers to written Chinese and English while "tri-lingualism" refers to spoken Cantonese, English and Putonghua. It is noteworthy that the policy is "bi-literacy" rather than "tri-literacy'. The term "Bi-literacy" does not distinguish between the

(C) 2012 Lee and Leung; licensee Springer. This is an Open Access article distributed under the terms of the Creative Commons Attribution License (http://creativecommons.org/licenses/by/2.0), which permits unrestricted use, distribution, and reproduction in any medium, provided the original work is properly cited. 
various different forms of written Chinese (e.g. traditional and simplified characters; Cantonese vocabulary and syntax). It is indisputable that the legal status of Cantonese was then firmly established for the first time officially. According to the census carried out by the SAR Government in 2001, 89.2\% of the population (about 5.72 million people) used Cantonese as their main daily language in a wide range of domains, such as interactions with family members, friends and colleagues, shopping and dining out, movies and television programmes, workplace meetings, court inquests, Legislative Council debates, the medium of instruction at schools, and government press releases. Hence, it is certainly not exaggerating to classify Cantonese as a major language used on a daily basis in Hong Kong.

Importantly, sociolinguists remind us that a society's language policy does not always match its demographics or daily language use as reflected in the census, but it often serves certain political and economic purposes (Spolsky 2004; Wright 2004; Guo 2004; $\mathrm{Xu}$ 2007), for instance, the promotion of Japanese in the Japanese occupied Korea and Taiwan in the first half of the $20^{\text {th }}$ century, and the French influences in modern Nigeria and Morocco. For Hong Kong, an international metropolitan city as well as one of the central administrative regions of China, the importance of English and Putonghua in Hong Kong is unquestionable. Indeed, the implementation of English and Putonghua is crucial to keeping Hong Kong going in this ever changing and highly globalized world, and the key to avoiding Hong Kong from being left behind. However, Cantonese as the most frequently used language should also be paid attention to for not only the local communication purpose, but also the regional cultural and identitybuilding reasons. Cantonese develops according to the particular needs of the people of Hong Kong, who share a way of life and culture, and it is clear that Cantonese is strongly intertwined with Hong Kong's sociocultural characteristics and identity. Thus, there will be cultural implication or social deprivation if the importance of Cantonese is undermined.

Nevertheless, if we take an in-depth investigation of the position of Cantonese in Hong Kong's official language policy at the levels of government, education and curriculum, it is found that neither the promotion nor the funding approaches on Cantonese match its legal status. Under the past policy of mother-tongue teaching, Cantonese was only a medium of instruction in CMI (Chinese as Medium of Instruction) schools instead of a learning subject. Students were required to attend oral and listening assessments of Cantonese, in the examinations of both the higher school level (secondary school: the Advanced-Level Examination, the Hong Kong Diploma of Secondary Education) and the lower level (primary school: the Territory-wide System Assessment) (HKEAA 2009). In addition, Territory-wide System Assessment has been a newly launched examination in recent years and the Oral and Listening examination in Cantonese was also a new attempt. These components in the examination system may imply that the Education Bureau still treated Cantonese as an important medium of instruction, or one may even argue Cantonese was not so well-regarded in the examination system before 1997 but has been given weight in recent years. However, there is apparently no systematic arrangement in the school curriculum to teach students the basic knowledge and daily applications of Cantonese.

In addition, there was very little mention of Cantonese teaching including Cantonese syntax, phonetics and pragmatics with regard to the relevant aspects of Chinese 
subject in the Hong Kong Certificate of Education Examination (HKCEE), a standardized examination after the completion of five years of secondary education. Strictly speaking, it is a common belief that the emphases on the three languages are based on reality because those three kinds of oral expressions have their irreplaceable functions as means of communication in different occasions. However, as a matter of fact it is quite demanding to expect every individual in the society to be biliterate and trilingual, i.e., to be conversant with written Chinese and English, and be able to speak fluent Cantonese, Putonghua and English (Lee and Leung 2010). To make good use of social resources for practical needs, there is no doubt that enough concern must be paid to "the most frequently used language" in both non-workplace and workplace situations before the implementation of the language policy of "bi-literacy and tri-lingualism".

In order to get a better understanding of the actual language situation in Hong Kong, we carried out a survey between June and August 2009 in Hong Kong Island, Kowloon and New Territories using a random sampling method. A total of 1004 people with different occupations were interviewed in regard to their language use in non-workplace and workplace situations. The statistics show that despite the uniqueness of English in some work-related circumstances, Cantonese is the language most frequently used. To put it simply, all the statistics point to the fact that Cantonese is the most common language in Hong Kong, whether in non-workplace or workplace situations.

In view of this, it is advisable for the related governmental departments to provide a package of effective language measures to schools to strengthen the basic learning of Cantonese, which is the mother language or first language of Hong Kong's majority (89.2\%). Likewise, it must be realized that the current teaching materials being used in the formal curriculum do not reflect the reality of the actual linguistic experience. Thus, to help students perform and learn better, it is preferable that the teaching materials should include target-oriented training with the focus on our daily life. The language use of those common types of occupation should also be included in the curriculum design.

The following section is a brief review of the status of Cantonese in Hong Kong from the levels of government, education and curriculum and relevant documents will be quoted. Section 3 outlines the actual language situation in Hong Kong using the results of selected surveys by the Hong Kong SAR Government, academic specialists and our research team. Section 4 points out that the current approaches on Cantonese promotion do not match its legal status or its actual use in both workplace and non-workplace situations, and provides some corresponding suggestions in the hope that the development of Cantonese teaching will not go in the opposite direction.

\section{The Position of Cantonese in the Current Education Policy}

Cantonese has gained its legal status under the "biliterate and trilingual" policy since 1997. To find out whether the actual position of Cantonese is equivalent to its legal status in the existing policy and whether enough resources have been put in for public promotion, we can take an in-depth look at the levels of government, education and curriculum. These three levels do not exist independently but are interdependent. In this section the adoption of the "biliterate and trilingual" policy by the SAR Government after the handover will be reviewed first. 


\subsection{At the Governmental Level}

In Hong Kong, the Policy Address (PA) is an annual ritual for the Chief Executive to present a programme of policies and his vision for the coming year. It is a combination of general themes and specific issues, detailing what challenges are confronting Hong Kong and what the proposed solutions are. In the 1997 Policy Address, the Chief Executive of the Hong Kong SAR Tung Chee-Hwa adopted the first-ever "biliterate and trilingual" policy to enable Hong Kong residents to become biliterate in written Chinese and English, and trilingual in spoken Cantonese, Putonghua and English. The statements are as follows (emphasis ours):

84. Confidence and competence in the use of Chinese and English are essential if we are to maintain our competitive edge in the world. The Education Commission Report No.6 has already laid down a framework to achieve our goal for secondary school graduates to be proficient in writing English and Chinese and able to communicate confidently in Cantonese, English and Putonghua. (1997 PA)

Actually back in March 1996, the Education Commission already considered that the policy of mother-tongue education should be reaffirmed and that a public education programme regarding the rationale of mother-tongue teaching should be strengthened (Education Commission, HKSAR 1996). After the handover, the biliterate and trilingual policy was promoted as a language-in-education policy for the very first time. Since then in the thirteen years from 1998 to 2010, the SAR Government has continued to emphasize the importance of "biliterate and trilingual" policy for another three times in the annual addresses:

69. It is the SAR Government's goal to train our people to be truly biliterate and trilingual. (1999 PA)

46. It is our policy to promote bi-literacy and tri-lingualism. Hong Kong is a cosmopolitan city, and it needs to promote the wider use of basic English. As part of China, Hong Kong people should also learn to speak fluent Putonghua. This will facilitate effective communication and business exchanges with the Mainland. (2001 PA)

90. Hong Kong's development is geared towards the provision of quality services to the Mainland and the rest of the world. To achieve this, we must upgrade our biliterate and trilingual proficiency. (2005 PA)

That is to say, it is widely recognized that the "biliterate and trilingual" policy is one of the goals to be achieved by the government after the handover. Hong Kong people, regardless of their job natures and education levels, are therefore expected to be biliterate in written Chinese and English, and trilingual in spoken Cantonese, Putonghua and English. It is also noticeable that in the Policy Address, the "biliterate and trilingual" policy and the job market in Hong Kong are closely linked together. In other words, this is an employment-oriented policy which is in response to the language needs of the working market. Under the trilingual policy, Cantonese equally shares the important status with Putonghua and English at face value. To promote the language policy efficiently, the SAR Government even began to implement the Chinese-medium 
instruction policy (or known as "mother tongue" education) in junior secondary schools between September 1998 and August 2010.

The importance of the implementation of Chinese-medium instruction policy was also emphasized in the Policy Address for three consecutive times from 1997 to 1999. This shows that however controversial the policy was, the SAR Government was determined to go for it.

85. Greater use of mother tongue teaching will help raise the standard of teaching in non-language subjects. It also allows more time to be given to specialised teaching of English and Chinese so that all language standards may be raised. (1997 PA) 97. We remain fully committed to the promotion of mother-tongue teaching. First, because expert opinion worldwide is that students learn best in their mother-tongue. Secondly, we are committed to improving the ability of our students to use Chinese and English. (1998 PA)

71. Mother-tongue teaching was introduced to help students learn more effectively. (1999 PA)

Besides the statements, there was no clear definition of "mother tongue" officially; however, "mother tongue" is believed to be equivalent to Cantonese from the context and its way of expression. In the "Report on Review of Medium of Instruction for Secondary Schools and Secondary School Places Allocation" delivered by the Education Commission (EC) in 2005, a noteworthy claim was made which serves as an indirect piece of evidence:

For the majority of Hong Kong population, Cantonese is most effective language to communication with one another and express views. The written form is Chinese.

It is beyond question that the "mother tongue" (or the first language) of most Hong Kong people is Cantonese, and so "mother tongue teaching" at schools is obviously "Cantonese teaching", although the authority has never used this term. But, in reality, the position and role of Cantonese teaching are not as clear as they should be. What "mother tongue" means remains ill-defined. Consequently, teachers are left to interpret whatever "mother tongue teaching" means to them in their context. Even though the society strongly demands the promotion of English teaching, it is indisputable, with a strong theoretical basis, that Cantonese, being the mother tongue (or the first language) of most Hong Kong people, is regarded as the most effective language in teaching. However, when it comes to Cantonese and Putonghua, some educators and language experts believe that under the "one country" principle, the promotion of Putonghua, instead of Cantonese, ought to be the trend, as Putonghua is the official language of China. To put it simply, after the handover, the general use of government funding on the promotion of the "biliterate and trilingual" policy sufficiently reflects the mainstream view on the teaching language of the Hong Kong society. Besides the regular funding for school operations to maintain an adequate teaching standard, a great part of the governmental funding goes to the Language Fund of the Standing Committee on Language Education and Research (SCOLAR)Standing Committee on Language Education and Research (SCOLAR) for language promotion. SCOLAR was a committee established in 1996 to advise the Government on language education issues in general and on the use of the Language Fund, as well as to oversee various 
Language Fund projects. In particular, SCOLAR advises on the policy on the medium of instruction and on the setting of language standards, including general goals for language learning at different levels of education and specific language attainment targets at each stage of education. The Language Fund of SCOLAR was established to support proficiency in the use of the Chinese (including spoken Putonghua) and English languages by the people of Hong Kong, and to fund programmes, projects, researches, textbooks, training courses, language teachers and educationists, and educational institutions which directly help the enhancement in the use of the Chinese and English languages in Hong Kong (Legislative Council Panel on Education 2001; SCOLAR 2003a, b). The activities funded by SCOLAR from 1998 to 2006 are highlighted as follows:

1998, 1999

SCOLAR endorsed a \$2.5 million budget for a three-year Summer Immersion Programme in Putonghua to support a total of 500 teachers. (16 December)

2000

SCOLAR endorsed a $\$ 50$ million budget for Workplace English Campaign. (28 February)

2002

SCOLAR spent $\$ 8$ million for the promotion of Putonghua. (7 March)

2003, 2004

SCOLAR organised the Putonghua Festival to promote the learning and use of Putonghua.

2005

SCOLAR presented the first-ever English Festival with seven lively English activities which were run from September 2004 to June 2005.

2006

SCOLAR sponsored English teachers of primary schools to attend overseas immersion programmes. (2 April)

At a superficial level, Cantonese obtained the same status as English and Putonghua under the trilingual policy, but unfortunately it can be seen from the funding items of SCOLAR that the resources for the promotion of the spoken languages were largely assigned only to English and Putonghua, and in particular billions of dollars have been invested to promote English since the handover in 1997 (Poon 2010). It was not until 2007 that the situation of neglecting Cantonese was slightly changed (see section 2.2). Concerning such a far-reaching language policy at the educational and curriculum levels, more will be given in the next subsections.

\subsection{At the Educational Level}

It is the governmental policy to promote bi-literacy and tri-lingualism in Hong Kong, and thus Cantonese, English and Putonghua are of equal status in principle. Nevertheless, when it comes to school teaching, Hong Kong society at large commonly believes that English and Putonghua teaching are more important than Cantonese teaching even if Cantonese is our mother tongue (or the first language) (Ming Pao 1997a, b). The followings are some highlights of the official statements related to local language teaching (emphasis ours), from which the orientation of Cantonese is nowhere to be found: 


\section{Policy Address}

69. We have established language benchmarks for those teaching English in junior secondary schools and Putonghua in primary schools. (1999 PA)

43. We need to train a critical mass of people with suitable talent as quickly as possible. These people should have a thorough understanding of the business environment of the Mainland, knowledge in international finance and commerce and proficiency in Putonghua and foreign languages, especially English. (2000 PA)

\section{Education Bureau}

1999 The SAR Government promotes benchmarking workplace English.

The Secretary for Education, Mr Michael Suen, announced that starting with the Secondary One level from the 2010-11 academic year, secondary schools may introduce different Medium of Instruction (MOI) arrangements to enrich students' Eng-

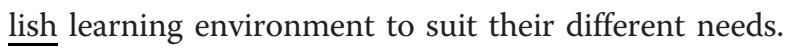

Standing Committee on Language Education and Research 2000

SCOLAR set up the Putonghua Summer Immersion Course Subsidy Scheme in 2000 to subsidise teachers to attend Putonghua summer immersion courses in the Mainland.

2004

SCOLAR set up the Professional Development Incentive Grant Scheme to encourage serving teachers of the English Language subjects to enhance their subject knowledge and pedagogy.

2006

SCOLAR has organised overseas immersion programmes for serving primary school English teachers since the 2006/07 school year to enhance their English language proficiency level and enrich their experience in English language teaching. 2007

SCOLAR launches the Quality English Language Education at Pre-primary Level Project in the 2007/08 school year to explore and develop more comprehensive models of quality English exposure of children at pre-primary level in Hong Kong. 2007

SCOLAR has introduced an Overseas Study Programme on English Language Education for Primary School Principals in Hong Kong since the 2007/08 school year.

2008

SCOLAR launched a support scheme in the 2008/09 school year to assist schools which have determination to use Putonghua to teach Chinese Language Subject through school-based on-site support by mainland professionals and local teachers who are experienced in using Putonghua to teach Chinese Language Subject. (3 January)

Indeed, SCOLAR has organized large-scale language activities every year since 2002 to provide a diversified and fun-filled environment for students to learn Putonghua and English and to create an atmosphere for the public to learn and use the two languages. In contrast, the proportion of government funding in certain areas regarding 
Cantonese is much lower. Under these circumstances, the development concerning the position of Cantonese in Hong Kong seems to be exactly in the opposite direction. It was not until 2007 that the situation changed to a small degree, when Cantonese pronunciation was included for the first time in the scoring system in the Chinese speaking test of HKCEE. The Standing Committee on Language Education and Research thus started to promote proper Cantonese pronunciation in response to this change:

SCOLAR started the promotion of proper Cantonese pronunciation in 2007 with a series of TV and radio programmes as well as school activities to encourage people to pronounce words in Cantonese properly without "lazy articulation" for better communication with other people. (SCOLAR 2007)

Moreover, SCOLAR joined hands with the Association for the Promotion of Proper Cantonese Pronunciation to organize the following activities to promote proper Cantonese pronunciation at school level:

(1) Proper Cantonese Pronunciation Ambassador in Schools Programme (2007/08 school year)

(2) Proper Cantonese Pronunciation Day Camp (2008/09 school year)

It is evident that those were the first-ever sponsorships SCOLAR used on the promotion of Cantonese since its establishment, despite the fact that it was limited to the pronunciation. In view of this, Cantonese teaching has undoubtedly long been neglected in the local education sector. This inadequate approach led to the lack of more rigorous and long-term planning of Cantonese teaching within the Chinese language curriculum, in which teaching objectives, teaching methods and teaching materials seem not to focus on the use and application of Cantonese in the society, nor the linguistic characteristics of the language. To further illustrate this point, we can refer to the HKCEE assessments for reading, writing, speaking and listening in the senior secondary Chinese subject as tabulated below:

From Table 1 it is obvious that Cantonese is involved only in the aspects of listening and speaking in the senior secondary Chinese subject. This is understandable because Cantonese is used mainly as a spoken language rather than in writing. Many Cantonese words actually do not have a written form. Some of the written Cantonese words are indeed made up along the way and there are now different ways of making up the writing of a Cantonese word. In a number of cases, people even put in an English word which is homophonous with a Cantonese word because of the absence of a written form. Written Cantonese can be considered a low form, as it never appears in formal communication, for example, in Government publications, formal business writing, and educational texts.

A noticeable point here is that at schools where Chinese is the medium of instruction (CMI), Cantonese is regarded as a medium of teaching and learning, but not itself the teaching and learning objective (Education Department 1997). In general, Cantonese as a functional language in Hong Kong is not taught syntactically and pragmatically at schools in spite of the fact that it is the major language of the majority of 
Table 1 Cantonese Involvement in the Four Aspects

\begin{tabular}{|c|c|c|c|c|}
\hline Aspects & \multicolumn{3}{|c|}{ Assessment Focuses } & $\begin{array}{c}\text { Cantonese } \\
\text { involvement }\end{array}$ \\
\hline Reading & \multicolumn{3}{|c|}{$\begin{array}{l}\text { The main aim of this part is to evaluate candidates' ability of using a variety of } \\
\text { reading strategies, including comprehension, analysis, feeling and appreciation. }\end{array}$} & Not applicable \\
\hline Writing & \multicolumn{3}{|c|}{$\begin{array}{l}\text { This part mainly assesses candidates on their ability in such areas as idea } \\
\text { construction, language expression and creativity. }\end{array}$} & Not applicable \\
\hline Listening & \multicolumn{3}{|c|}{$\begin{array}{l}\text { Candidates are required to demonstrate their listening ability of distinguishing the } \\
\text { standpoints, opinions, oral skills and tone of the speakers. }\end{array}$} & $\begin{array}{c}\text { The materials } \\
\text { are recorded in } \\
\text { Cantonese. }\end{array}$ \\
\hline \multirow[t]{2}{*}{ Speaking } & \multirow[t]{2}{*}{$\begin{array}{l}\text { Candidates are examined on } \\
\text { their ability of oral } \\
\text { presentation, communication } \\
\text { and interaction. }\end{array}$} & Reading Aloud & $\begin{array}{l}\text { This subpart mainly assesses } \\
\text { candidates on their ability of } \\
\text { reading texts aloud with } \\
\text { appropriate pronunciations, tones } \\
\text { and rhythms. }\end{array}$ & \multirow[t]{2}{*}{$\begin{array}{l}\text { This part will } \\
\text { be conducted } \\
\text { entirely in } \\
\text { Cantonese. }\end{array}$} \\
\hline & & $\begin{array}{c}\text { Oral } \\
\text { Communication }\end{array}$ & $\begin{array}{l}\text { In this subpart, candidates are } \\
\text { expected to demonstrate } \\
\text { expression, interaction, } \\
\text { communication skills in the } \\
\text { discussions. }\end{array}$ & \\
\hline
\end{tabular}

Hong Kong population as well as the most frequently used language in the workplaces (section 3.3).

\subsection{At the Curriculum Level}

To investigate the status of Cantonese in the current Chinese curriculum under the biliterate and trilingual policy, we can further examine the involvement of Cantonese in the four main aspects in the three most frequently used textbooks (Zhang 2011) for the senior secondary Chinese language in Hong Kong schools. The textbooks are as follows:

(1) Keys New Senior Secondary Chinese Language (Keys Press 2009)

(2) New Senior Secondary Chinese Language (New Edition) (Hong Kong Educational Publishing 2005)

(3) Longman Senior Secondary Chinese Language (Longman Hong Kong Education 2005)

Concerning the cultural diversity of Hong Kong as an international city, there are many different language policies in education if one takes into consideration all the international schools, ESF schools, etc. This paper only focuses on those that follow the EDB curriculum. Table 2 shows the contents involving Cantonese in Form Four textbooks as an example. Similar to the HKCEE assessments, Cantonese is basically involved in the aspects of listening and speaking. This is not surprising because the content design of the textbooks of the Chinese language is principally based on the HKCEE grading criteria.

Virtually, some Hong Kong people hold the point that training in the use of Cantonese is unnecessary as it is their mother tongue (Lee and Leung 2010). According to a survey (section 3.3) done by Lee and Leung in 2009, part of which is concerned with the respondents' attitudes towards languages used in Hong Kong, over 50\% people replied that if they had the resources, they desired to improve their language proficiency in English or Putonghua, and that for Cantonese, being able to conduct the 
Table 2 Cantonese Involvement in the Three Most Frequently Used Textbooks

\begin{tabular}{|c|c|c|c|c|}
\hline \multirow[t]{2}{*}{ Publishers } & \multicolumn{4}{|c|}{ Aspects } \\
\hline & Reading & Writing & Listening & Speaking \\
\hline \multirow[t]{2}{*}{ Keys } & $\mathrm{Nil}$ & $\mathrm{Nil}$ & $\begin{array}{l}\text { The materials } \\
\text { are recorded } \\
\text { in Cantonese }\end{array}$ & $\begin{array}{l}\text { - Cantonese pronunciations provided } \\
\text { for new or difficult words. }\end{array}$ \\
\hline & & & & $\begin{array}{l}\text { - Standard Cantonese pronunciation is } \\
\text { required. There are also explanations } \\
\text { for variant pronunciations. }\end{array}$ \\
\hline \multirow[t]{2}{*}{ HKEP } & $\mathrm{Nil}$ & $\mathrm{Nil}$ & $\begin{array}{l}\text { The materials } \\
\text { are recorded } \\
\text { in Cantonese }\end{array}$ & $\begin{array}{c}\text { - Cantonese pronunciations provided } \\
\text { for new or difficult words, as well as } \\
\text { for those which are easily pronounced } \\
\text { wrong. }\end{array}$ \\
\hline & & & & $\begin{array}{c}\text { - Separate lessons on speaking training } \\
\text { for the purpose of correcting } \\
\text { Cantonese pronunciations with the } \\
\text { illustration of Cantonese phonological } \\
\text { rules. }\end{array}$ \\
\hline \multirow[t]{3}{*}{ Longman } & $\begin{array}{l}\text { Limited Cantonese idioms are } \\
\text { introduced as reading topics } \\
\text { in the integrated part. }\end{array}$ & $\mathrm{Nil}$ & $\begin{array}{l}\text { The materials } \\
\text { are recorded } \\
\text { in Cantonese }\end{array}$ & $\begin{array}{l}\text { - Cantonese pronunciations provided } \\
\text { for new or difficult words. }\end{array}$ \\
\hline & & & & $\begin{array}{l}\text { - Basic phonetic knowledge of } \\
\text { Cantonese is provided. }\end{array}$ \\
\hline & & & & $\begin{array}{l}\text { - There are certain exercises on } \\
\text { Standard Cantonese pronunciation. }\end{array}$ \\
\hline
\end{tabular}

daily conversations is enough. But we must realize that, as the linguists emphasize, being able to speak and understand a language does not mean that one "knows about" the language. In addition to this, some of the educators even have the belief that promoting English and Putonghua should be the right direction, and that Cantonese is just a transitional medium of instruction. Under these circumstances, the current speaking training of Chinese subject always focuses on the basic ability and lacks longterm planning. When teaching objectives, teaching methods and teaching materials are not in response to the pragmatic needs of the job market, there will be a negative impact on the implementation of the trilingual policy. Hence, we are convinced that some relevant surveys should be carried out to lay the research foundation before the implementation of any major education policy and the design of Chinese language curriculum.

In the next section, selected surveys carried out by different researchers on language use in Hong Kong will be presented; the survey in section 3.3 was conducted by our research team in 2009 and is believed to be the most up-to-date one of its kind.

\section{The Language Situation of Hong Kong}

\subsection{Surveys by the Hong Kong SAR Government}

In Hong Kong, there have been different kinds of surveys on language use every now and then serving a multitude of purposes. Among those surveys, the population census by the Census and Statistics Department of the Hong Kong SAR Government is widely recognized as the most representative. The population census is a large-scale sample enquiry of socio-economic characteristics of the population. From 1961, it is established practice in Hong Kong to conduct a population census (PC) every ten years and a by-census $(\mathrm{BC})$ in the middle of the intercensal period. The sampling fraction is approximately one-tenth and a scientific sampling scheme is adopted. Following 
this practice, the latest population by-census was conducted in mid-2006 and around 220000 households in Hong Kong were enumerated. According to the Census and Statistics Department, the aim of conducting population censuses and by-censuses is:

to obtain up-to-date benchmark information on the socio-economic characteristics of the population and on its geographical distribution. They provide benchmark data for studying the direction and trend of population changes. The data are key inputs for making projections concerning population, household, labour force and employment. Population censuses/by-censuses differ from other general household sample surveys in their sizable scale which enable them to provide statistics of high precision, even for population sub-groups and small geographical areas. Such information is vital to the Government for planning and policy formulation and important to the private sector for business and research purposes. (page 2, Statement on 2006 Population By-census: Hong Kong, China)

Data collection of the population census is normally carried out by the "interviewer" method. Strictly selected field workers, most of which are school teachers and postsecondary students, pay visits to the sampled households and question each individual in such households to complete the questionnaires. Apart from the "interviewer" method, an online questionnaire was first introduced in 2006 for those households and persons who opt for the choice of electronic data reporting. Table 3 illustrates the statistics on language use in Hong Kong in 1991(PC), 1996(BC), 2001(PC), 2006(BC) (Census and Statistics Department 1991, 1996, 2001, 2006).

We can get a better understanding of the number and percentage of local language use from the table. These data are extremely useful for outlining a comprehensive picture of language distribution in Hong Kong for the last two decades. Unfortunately, such investigations do not consider how the contexts influence the use of languages because "usual language" is not equivalent to "the only language that one can speak". For example, the usual language of an interviewee can be Cantonese but in reality he or she is also expected to use both Putonghua and English in certain scenarios. Obviously, it is a pity that the current design of population census fails to provide more information for further analysis.

\subsection{Surveys by Academic Specialists}

In contrast to population census, owing to limited resources the scales of research projects on language use led by academic specialists are not as large as the ones by the

Table 3 Population Aged 5 and Over by Usual Language (\% of total)

\begin{tabular}{lcccc}
\hline Usual Language & $\mathbf{1 9 9 1}$ & $\mathbf{1 9 9 6}$ & $\mathbf{2 0 0 1}$ & $\mathbf{2 0 0 6}$ \\
\hline Cantonese & 88.7 & 88.7 & 89.2 & 90.8 \\
Putonghua & 1.1 & 1.1 & 0.9 & 0.9 \\
Other Chinese Dialects & 7.0 & 5.8 & 5.5 & 4.4 \\
English & 2.2 & 3.1 & 3.2 & 2.8 \\
Others & 1.0 & 1.3 & 1.2 & 1.1 \\
Total & 100.0 & 100.0 & 100.0 & 100.0 \\
\hline
\end{tabular}

Note: The figures exclude mute persons. 
Census and Statistics Department. Nevertheless, since their research focuses are comparatively clear, usually they are able to collect more detailed and in-depth information than the population censuses. Tsou is a pioneer in such area among the local sociolinguists; he conducted a survey on the use of family language of the middle class in Hong Kong in as early as 1977 (Tsou and You 2007). The results are found in the work A Course in Sociolinguistics which generates quite a great impact on the related research area. For instance, when a recent work Language Situation in China (Language Situation in China Group 2005) discusses the language situation and policy in Hong Kong after the handover to China in 1997, the authors still follow Tsou's ideas as far back as 1977. However, Tsou's survey of the middle class was made 30 years ago, and so it is reasonable and also necessary to conduct another investigation to collect some new data since there have been significant changes in different aspects of Hong Kong society over the past three decades.

There was a long period of silence on language investigation with a great impact after Tsou, until Hong Kong's handover to China. During this historic period, many scholars hoped to document the change of language use in Hong Kong for English was believed to step out of the history gradually and be replaced by Putonghua, the official language of China. However, the scales of those researches are not large enough to make a convincing and scientific conclusion, and their focuses are always too narrow to build up a whole picture of actual language use in Hong Kong. For instance, Li (1996) indicates that Cantonese-English code-switching is a typical language convention in the society and it tends to be intra-sentential. Long (1998) and Gao et al. (1998) are interested in Hong Kong people's attitudes toward Cantonese and Putonghua both quantitatively and qualitatively. Afendras (1998) focuses on the language use at homes and reports in his survey that Cantonese is the mealtime language while half of the children interact in English with the Filipino maids. Long (1999) remarks on the language used in the workplace setting. Evans et al. (1998) interview a good number of students, teachers, parents and business people for rating students' ability in English, when the mother-tongue education was implemented for the first year. Those researches certainly have emphases of their own, but none of them involves the functions of Cantonese, English and Putonghua in different circumstances separately. Therefore, they could only reflect the language picture of Hong Kong partially.

In the first decade of the establishment of the SAR Government, to match up the new change with suitable local language policies, Putonghua was introduced into the school curriculum under the unprecedented education reforms (Education Commission 2005Education Commission 2005). Educationalists were interested in discussing whether Putonghua or English would be the more suitable language as medium of instruction for students, which was later known as the CMI-EMI dispute (Tse et al. 2001; Poon 2004; Ng 2007; Evans 2009). The investigation of Cantonese language use was thus apparently reduced and consequently the influential data were lacking. (Education Bureau (EDB) of Hong Kong).

In the hope of providing new and accurate statistics for different types of investigations, including academic researches and policy discussions, our enquiry in 2009 gives an account of language use in Hong Kong and is the most updated one at the present time. 


\subsection{Survey in 2009}

In order to investigate the actual use of language in Hong Kong and to increase the representativeness of the research data, a survey was carried out in Hong Kong Island, Kowloon and New Territories from June to August 2009. We conducted face-to-face interviews in shopping malls and on the streets, the respondents were selected at random for the interviews, and a total of 1004 valid questionnaires were collected and used for the final analysis. The main focus of the survey was to identify the proportion of the language use in the respondents' daily life, including in workplace and nonworkplace situations.

The questionnaire was divided into three parts. The first part was concerned with the basic backgrounds of the respondents, including their mother languages, ages, education levels, occupation types and positions, and the cities in which they had lived the longest. The second part focused on the frequency of use of languages in the workplaces and non-workplaces. Non-workplace activities include conversations with family members and friends, shopping and dining out, watching TV, listening to the radio, and taking part in the cultural and recreational activities. Workplace activities include conversations with superiors, subordinates, and colleagues on the same level, clients, other organizations and enterprises, departments of the government, meetings and casual talks. A six-point scale was used in this survey, measuring either a positive or negative response to a statement. The six-level items were: 5-most frequently used, 4frequently used, 3-generally used, 2- infrequently used, 1- most infrequently used and 0 -never used.

The third part dealt with the respondents' attitudes towards the Cantonese language, including which language can best express their thoughts and emotions, the importance of Cantonese in Hong Kong, the advantages of learning and mastering the Cantonese language, and at what proficiency level they think their Cantonese is. Similar to part two, a six-point scale was employed in measuring a positive or negative response to a statement. The highest score was 5 which indicated "very important", while 4 and 3 represented "important" and "generally important" respectively, 2 and 1 indicated "unimportant" and "very unimportant" whereas 0 was the lowest score which meant "completely not necessary".

\subsubsection{Basic particulars of respondents}

A total of 1004 individuals were successfully interviewed in this study; Table 4 shows the basic particulars of the respondents, including gender, age, educational level and occupational rank.

It is noted that the percentage of male and female respondents in this study is similar to the 2006 by-census data of the Hong Kong Census and Statistics Department. Nevertheless, since the design of this study is related to the workplace, those already retired or not yet entered into the workplace did not complete the whole questionnaire. Hence, as the final completion of the questionnaire is concerned, respondents aged from 19 to 50 years old are almost 90\% which is higher than the population percentage in Hong Kong. With regard to the educational level, the number of Form 5 to bachelor's degree holders reached 90\%, also higher than the population percentage. As for the work nature, generally the percentage shown in our study is close to that of the overall population, except for the percentage of administrative staff and senior executives which is lower than the 2006 by-census data (10.8\%). 
Table 4 Basic Information of the Respondents

\begin{tabular}{llcc}
\hline Item & & Number & Percentage \\
\hline Gender & Male & 478 & $47.6 \%$ \\
& Female & 526 & $52.4 \%$ \\
\hline Age & 18 or under 18 years old & 63 & $6.3 \%$ \\
& $19-30$ years old & 533 & $53.1 \%$ \\
& $31-40$ years old & 200 & $20 \%$ \\
& $41-50$ years old & 146 & $14.5 \%$ \\
& Above 50 years old & 62 & $6.2 \%$ \\
\hline Educational Level & Primary & 23 & $2.3 \%$ \\
& Secondary - Form 5 & 360 & $35.9 \%$ \\
& Secondary - Form 7 & 135 & $13.4 \%$ \\
& Bachelor Degree & 413 & $41.1 \%$ \\
& Master Degree & 63 & $6.3 \%$ \\
& Doctoral Degree & 8 & $0.8 \%$ \\
\hline Occupational Rank & General clerical and technical work & 629 & $62.8 \%$ \\
& Professionals, associate professionals and middle managers & 314 & $31.3 \%$ \\
& Administrative staff and senior executives & 59 & $5.9 \%$ \\
\hline
\end{tabular}

\subsubsection{The Comparison of the Use of the Three Languages in Non-workplace and Workplace}

\section{Situations}

This subsection concerns the preliminary statistics of our investigation. Figure 1 is the distribution of the frequency of use of Cantonese, English and Putonghua in non-workplace and workplace situations.

As shown in the figure, Cantonese is the most often used language in both nonworkplace and workplace settings with the means of 4.84 and 4.60 respectively, very close to the level of "most frequently used". English accounts for the second, its means in non-workplace and workplace settings being 1.24 and 1.34, in between the levels of "most infrequently used" and "infrequently used". Despite the promotion of Putonghua after the handover, its mean is the lowest among the three languages, with only 0.72 and 0.66 in non-workplace and workplace settings respectively, in between the levels of "never used" and "most infrequently used".

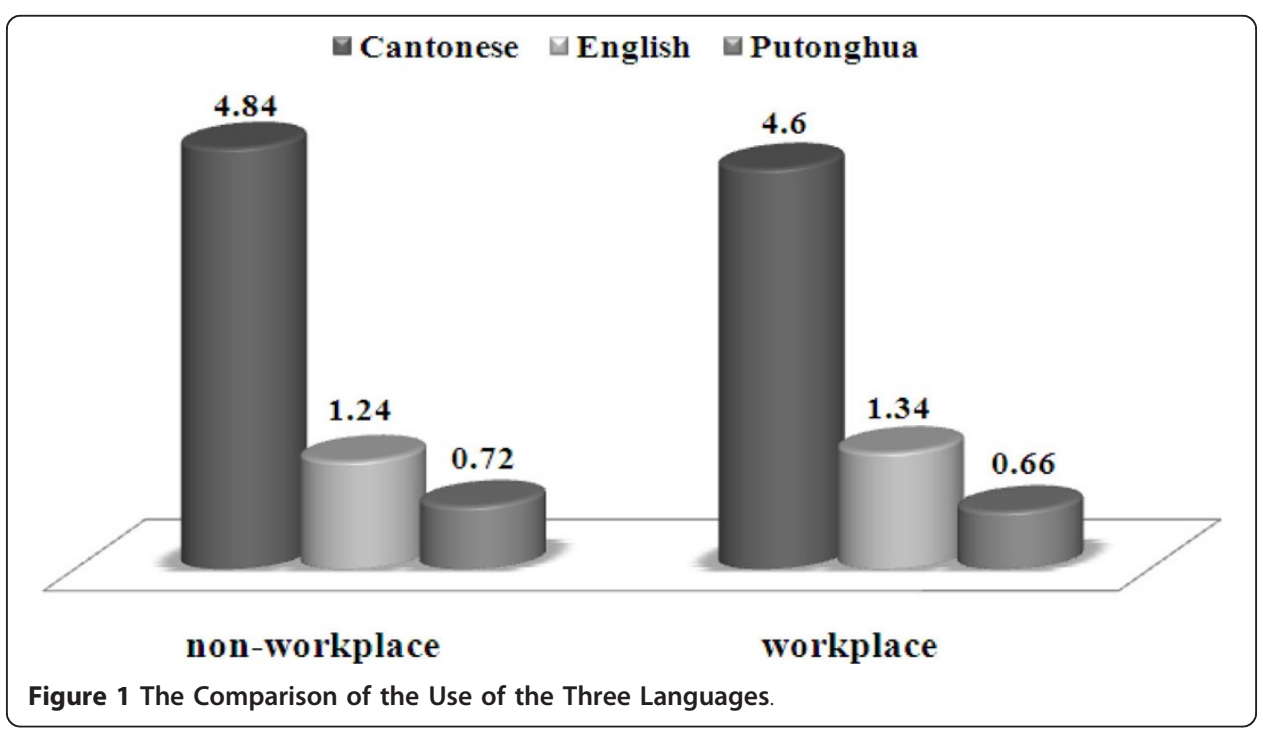


In brief, the mean frequency of use of Cantonese is much higher than those of the other two languages. It is interesting that the use of Cantonese and Putonghua in nonworkplaces is more frequent than in workplaces. In contrast, the use of English in workplaces is more often than in non-workplaces. In other words, those who are familiar with Cantonese use English at work in certain occasions. Besides, unlike the situation in other multilingual Asian cities such as Singapore, the opportunity and need of the majority of the Hong Kong people to use spoken English to communicate are not socially extensive, and the discrepancy mentioned above, however, suggests that English has unique and important functions irreplaceable in the workplaces even though its actual frequency of use is far lower than that of Cantonese. There is thus always societal support for English teaching at schools, regardless of the little support to provide situations in which people use English for real communicative purposes outside classrooms. Moreover, the data of the following table, which shows the frequency of use of Cantonese, English and Putonghua in different occasions, further illustrate the special status of Cantonese. In Table 5, the first occasion "family members" refers to the question of which language the respondents often used to chat with their family members. The rest can be comprehended in the same manner.

It is obvious from the table that the mean of Cantonese is approximately 4.90 in the occasions of conversations with family members, friends, shopping and dining out. The result reflects that, despite the close relationship with Mainland China having increased the accessibility of Putonghua (HKSAR 2008; ACCHK 2008), Cantonese is still the primary language used by the respondents on a daily basis, while it is also common for them to use English or Putonghua or even both in the workplaces as mediums. In particular, when they have business conversations with their clients and potential partners, the chances of using English or Putonghua will be higher. English is always on the top priority of language usage as Hong Kong is an international centre of trade, finance and communications.

\section{Discussions and Conclusions}

\subsection{At the Governmental Level}

From the extracts of Policy Address shown in section 2.1, the "bi-literacy and tri-lingualism" policy has been both the centre and guideline of the language policy since the handover in 1997. This language reform is extraordinarily important because it had a

Table 5 Distribution of Use of Cantonese, English and Putonghua

\begin{tabular}{|c|c|c|c|c|c|c|}
\hline \multicolumn{7}{|c|}{ Non-workplace } \\
\hline $\begin{array}{l}\text { Occasion } \\
\text { Language }\end{array}$ & $\begin{array}{l}\text { Family } \\
\text { members }\end{array}$ & Friends & Shopping & Dining out & $\begin{array}{l}\text { TV \& } \\
\text { radio }\end{array}$ & $\begin{array}{c}\text { Cultural \& } \\
\text { recreational activities }\end{array}$ \\
\hline Cantonese & 4.90 & 4.93 & 4.97 & 4.97 & 4.79 & 4.47 \\
\hline English & 0.57 & 0.99 & 0.41 & 0.43 & 2.49 & 2.53 \\
\hline Putonghua & 0.39 & 0.59 & 0.21 & 0.16 & 1.44 & 1.54 \\
\hline \multicolumn{7}{|l|}{ Workplace } \\
\hline $\begin{array}{l}\text { Occasion } \\
\text { Language }\end{array}$ & $\begin{array}{l}\text { Same-level } \\
\text { colleagues }\end{array}$ & Superiors & Subordinates & $\begin{array}{l}\text { Business } \\
\text { partners }\end{array}$ & Clients & Meetings \\
\hline Cantonese & 4.73 & 4.53 & 4.77 & 4.43 & 4.61 & 4.53 \\
\hline English & 1.18 & 1.24 & 0.66 & 1.72 & 2.00 & 1.22 \\
\hline Putonghua & 0.57 & 0.37 & 0.39 & 0.83 & 1.43 & 0.37 \\
\hline
\end{tabular}


considerable impact on local language education by challenging the past unique status of English as the medium of instruction (Chang 1979; Pennington and Yue 1994), and later raised more questions on its effectiveness and advantages than solutions to enhance students' language ability (Poon 1999; Li 2009). For example, there was the dispute on the medium of instruction at schools, and on whether to use Putonghua or Cantonese to teach Chinese (Poon 2000). Under the trilingual policy, Cantonese has an official status, but in reality the promotion of Cantonese educationally is not as clear as it should have been. The disproportionate funding of SCOLAR also did not match the governmental goal of the implementation of the "biliterate and trilingual" policy. Some people even hold the following concept which is certainly hindering the future promotion of Cantonese teaching:

(In Hong Kong after the handover) Mandarin will become the political and administrative language and English will become the language in such areas as science, technology, finance and business while Cantonese will only be an informal language used in the family and situations between acquaintances. (Huang 1997)

However, as evident in the most up-to-date survey in 2009 (section 3.3), the mean frequency of use of Cantonese is higher than those of English and Putonghua. The claim of Cantonese being an informal language is therefore not only distant from the reality of language situations in Hong Kong but also undervalues the pragmatic functions of Cantonese. In fact, it is a language used in various fields such as politics, economics, culture, religion and education, as well as some other important occasions like Legislative Council debates. If the similar language situation applies to other countries or regions, the authorities concerned will adopt relevant long-term policy to promote and protect such a widely used and functional language. But irrationally the opposite happened in Hong Kong, as we have seen in section 2.1 that the funding focus for the promotion of the spoken languages of SCOLAR was basically on English and Putonghua only. We believe that the three languages are all needed in both workplace and non-workplace situations in Hong Kong because of their specific functions and characteristics. Yet, besides how tremendous the public funds were launched, we should realize in the first place that for the common people, being fluent in all the three languages is quite high a requirement.

With the above observations in mind, it is advisable that we should rethink about the problems in the current language policy and how to perfect it, especially since language policy in education is always related to questions of identity in a society (Tsui 2007). It is ironic that most of the jobs in Hong Kong do not require a trilingual employee (section 3.3.2 and Figure 1). If the majority part of the work only requires one or two languages and our basic education develops the trilingual capability simultaneously, this will undoubtedly waste a lot of resources and keep our students from acquiring knowledge of other subjects. Hence, it is unwise to neglect the involvement of the most commonly used language in the implementation of any language policy.

As mentioned early on in this paper, a society's language policy does not always match its demographics and the actual language use but often serves the political and economic purposes. To make sense of the current recommendations of this issue, the ideological aspect of language policy in China should also be taken into consideration. 
It is known that Putonghua is the official language of China and is used for the nation's political, diplomatic, social, educational and commercial areas, but there are also many other dialects in China. The constitution of China contains an assurance that ethnic minorities within the 148 autonomous areas of the China can use their own languages (Ma 1985; Mackerras 2003). The implementation of minority languages as a medium of instruction can increase attendance rates and strengthen socialization into national ideologies (Bake 2001; Qi 2004; Spack 2002; Street 2001). Thus, it is clear that China provides minority groups with bilingual education in order to produce competence in both their ethnic language and Putonghua (Teng 2000). According to Zheng (2002), 12 minority scripts are used in both primary and secondary school textbooks and nine more are being piloted in the schools. China also produces 300 textbook titles in more than 30 ethnic minority languages. Under the protection of the constitution, most minority languages in China are still in surprisingly good shape.

In Hong Kong, there have been widespread efforts to promote the usage of Putonghua since the handover in 1997. China has promoted Putonghua throughout the whole country since its finding in order to remove barriers caused by dialectical differences (Beijing Languages Institute 1995). This goal to unite the various peoples and bring about a further political, cultural, and economic development also applies to Hong Kong's society. The impetus to promote Putonghua in Hong Kong comes from three linked ideas: (1) Putonghua is the official language of China, (2) Hong Kong has an interdependent relationship with China, and (3) the local culture of Hong Kong is Chinese culture (Wilkinson and $\mathrm{Lu}$ 2001). Therefore, it is expectable and understandable that Putonghua has been emphasized in the last decade. Since it is conceivable that promoting Putonghua and promoting Cantonese in the language-in-education policy are not contradictory but rather in accordance with the policy of "dialect bilingualism" (Erbaugh 1995; cf. Bauer 2000) protected by the country's constitution, the SAR Government could carefully consider Hong Kong's own situation and fine-tune the current language policy by putting in more resources to promote Cantonese under the principle of "one country and two systems" which is assured by the Basic Law.

We suggest the SAR Government review the existing language policy, define the relationship between Cantonese, English and Putonghua clearly, and evaluate the policy systematically from theoretical and practical levels so as to ensure that Cantonese, the local common language, is used in public contexts for high-level functions, including situations of workplace and non-workplace.

\subsection{At the Educational Level}

Instead of sharing the equal status with English and Putonghua under the trilingual policy, the current development concerning the position of Cantonese in Hong Kong seems to have been in exactly the opposite direction for a long time (section 2.2). To empower Hong Kong people to adjust to the working environment and contribute more to their career, the education policymakers are expected to consider how Cantonese teaching should be promoted at both social and educational levels, with the recognition of the fact that Cantonese is the dominant language in Hong Kong (section $3)$. Fortunately, the situation of neglecting Cantonese changed to a small degree in 2007, when Cantonese pronunciation was included in the Chinese speaking examination in the HKCEE. In response to this, the SCOLAR started to encourage people to 
pronounce Cantonese words properly with a series of TV and radio programmes as well as school activities for the purpose of enabling "better communication with other people". It is a good starting point for the first-ever promotion of Cantonese, but this move did not change the fact that Cantonese is still given a lower priority among the three languages.

Being the department directly responsible for implementing the "bi-literacy and trilingualism" policy, the Education Bureau is advised to redefine the position of Cantonese in the current language education. Not only is Cantonese to be used as the medium of instruction at schools, but a planned and focused curriculum regarding practical Cantonese should also be designed to include Cantonese elements so as to let the students prepare well for their future employment. This language approach can help our next generations live and work better. Moreover, to successfully implement the trilingual goal, we suggest that an appropriate school curriculum should be one which is able to demonstrate the use of Cantonese in different contexts with the actual language environment, and to enable the students to learn the all basic linguistic features of the Cantonese language for effective communication, rather than just pronunciation.

Furthermore, as we have seen, the materials used in both listening and speaking parts in the HKCEE are conducted in Cantonese (section 2.2). If the student is unfortunately weak in Cantonese, he or she will not be able to distinguish between the standpoints and tone-of-voice of the speakers in the listening test, and to communicate appropriately in the speaking part. Therefore, it is clear that the training of spoken Cantonese plays a very important role in basic education and public examinations. The existing curriculum emphasizes only the general speaking skills, and is probably inadequate in its training of communicative competence in Cantonese in various linguistic contexts. Also, there is no focus on the stylistic features of Cantonese, regardless of teaching objectives, teaching methods and teaching materials. Take the Suggested Learning Objectives of Chinese Language in Secondary Schools (Trial Version) (Curriculum Development Council 2006) for example, the learning objectives of the speaking part are only listed out in general, yet the important pragmatic differences between Cantonese and Putonghua are for some reason not noticed. Accordingly, for successful policy implementation and appropriate design of Cantonese curriculum, the language situation in Hong Kong and the linguistic features of Cantonese should receive enough attention from various stakeholders in the education sector.

\subsection{At the Curriculum Level}

The actual language situation in Hong Kong reflected by the different surveys is that Cantonese is the major language spoken in both workplace and non-workplace situations, and it is also the language used in the listening and speaking tests of the HKCEE. All these characteristics form the ground for the establishment of an integrated curriculum of Cantonese training. It is suggested that such a package of teaching materials should have diverse and focused themes which are close to the students' real experience in daily life and growing backgrounds.

Regarding the selection of the contents, the design of the materials can be more career-oriented to include the use of Cantonese in various workplace contexts, and to introduce the features and characteristics of the Cantonese expressions used in the 
most common jobs. It is also advisable to combine the situations of workplace and non-workplace in the curriculum design, because the integrated topics would be useful to the senior students, helping them strengthen their linguistic knowledge on the Cantonese language, master the useful and skilful expressions, and realise the trend of the job market better. For instance, in the context of dealing with personal financial matters in the banks, the focus of the design should include both the staff and customers, particularly the former (Huang 2009).

Despite the fact that there seem to be no such resources for local Cantonese native speakers, this kind of work-related teaching resources are virtually common for the non-Cantonese native speakers who are working in Hong Kong, for example, the teaching materials of Cantonese designed by the Language Centre of Hong Kong Baptist University (n.d.) for the mainland Chinese and the Yale-China Chinese Language Centre of the Chinese University of Hong Kong (n.d.) for the non-Chinese ethnic groups. The materials include aspects of Cantonese phonetics, lexicon and syntax and obviously aim at enhancing the learners' ability of oral communication through targeted training in different contexts. Other than this, there are also some local language schools which launch the Cantonese programme with various focuses, for instance, the local Pasona Education (n.d.) provides Cantonese training particularly for Japanese people by training them with real life and business expressions. Besides, local Cantonese culture, Cantonese expressions in school campuses or those with unique and interesting features can also be included as part of the learning aspects, like the materials for the students of Southeast Asian descent made by Delia Memorial School (Broadway) (2003) and for the students from mainland China made by the Hong Kong University of Science and Technology (n.d.). Stand-up comedy, which is a very local performance, is also a good resource for learning Cantonese idioms and slang.

Secondly, regarding the linguistic features of Cantonese, the materials on teaching Cantonese as a second language can be of use for further references (Yip and Matthews 2006; Tong and James 2007). These works focus on Cantonese in different contexts with separate topics, and relevant information on phonetics and syntax is sometimes also provided. More advanced monographs such as Matthews and Yip (1994) and Cheung (1972/2007) can serve as additional references. What's more, from the language stylistic viewpoint, the characteristics of Cantonese formal speech are apparently very different from those of Putonghua in mainland China. If these speech features of Cantonese can be taught in the basic school curriculum, this would help upgrade the effective application into a wide range of areas.

Lastly, it is beneficial for the learners if the modes of teaching can be more diverse, for example, demonstrating the lesson content with the means of movies which portray the real daily life of modern Hong Kong people. Through the movie scenes and scripts, students can recognize and understand what is key to effective communication by directly observing the tone-of-voice, intonation and nonverbal performance such as gestures of the speakers. Learning Cantonese in three months (Jia 2008) is an example of this kind of teaching materials.

In short, the SAR Government should not keep on turning a blind eye to the actual language situation and always placing priorities merely on the promotion of English and Putonghua. Instead, it should take the initiative to allow Cantonese a "real" official status, rather than just giving a lip promise, particularly in basic language education, as 
well as to convince the educational stakeholders to show positive attitudes towards Cantonese teaching in the Chinese curriculum by putting in more resources.

\section{Competing interests declaration}

The authors stated that they had no interests which might be perceived as posing a conflict or bias in the collection and interpretation of the data.

\section{Acknowledgements}

This study is part of a research project entitled "A Preliminary Investigation into the Use and Stylistic Features of Hong Kong Cantonese". The project was financed by the Hong Kong Institute of Education and ran from 2009-2010. Dr LEE Kwai-Sang and Dr LEUNG Wai-Mun were members of the research team.

\section{Authors' contributions}

Both authors had equal responsibility in designing the questionnaire interview, data analysis and writing the paper. Both read and approved the final manuscript.

\section{Authors' Information}

Dr LEE Kwai Sang is currently the Associate Head and an Associate Professor at the Chinese Department of the Hong Kong Institute of Education. He obtained his PhD in Chinese Language and Literature at The Chinese University of Hong Kong. His research interests include Literary Theory and Criticism, Pre-modern Chinese Literature, Intellectual History of China, and Cantonese in Hong Kong Society. He has published two books on Chinese Mythology and Classical Chinese Literary Criticism respectively, and over twenty book chapters and articles in well-known refereed journals such as Bulletin of the Institute of Chinese Literature and Philosophy, Chinese Studies, and Journal of Chinese Studies.

Dr LEUNG Wai Mun is currently an Assistant Professor in the Chinese Department at the Hong Kong Institute of Education. She completed her doctoral studies at the Department of Linguistics, The University of Hong Kong in 2006. Her chief areas of research interests are related to the study of syntax, phonetics, text analysis and sociolinguistics. She has written a book on Cantonese sentence-final particles, and a number of academic papers in refereed journals such as Sino-Humanitas, Studies in Chinese Linguistics, International Journal of Linguistics, Journal of Chinese Literary Studies, Asian Culture and History, Asian Social Science and Cantonese Studies.

Received: 29 July 2011 Accepted: 9 January 2012 Published: 9 January 2012

\section{References}

Afendras, EA. 1998. The Onset of Bilingualism in Hong Kong: Language Choice in the Home Domain. In Language in Hong Kong at Century's End, ed. Pennington MC. 113-114. Hong Kong: Hong Kong University Press.

Baker, C. 2001. Foundations of Bilingual Education and Bilingualism, 3rd edition. Clevedon, England; Buffalo, NY: Multilingual Matters.

Bauer, RS. 2000. Hong Kong Cantonese and the road ahead. In Language and education in postcolonial Hong Kong, ed. Li CS, Lin A, Tsang WK. 35-58. Hong Kong: Linguistic Society of Hong Kong.

Beijing Languages Institute. 1995. Practical Chinese reader I. Beijing: The Commercial Press.

Census and Statistics Department. 1991. Report of the census. Hong Kong: Government Printer. 1996, 2001, 2006.

Census and Statistics Department of Hong Kong SAR. http://www.censtatd.gov.hk. Accessed: 20 Oct 2009.

Cheng, NL. 1979. Issues in language of instruction in Hong Kong. Hong Kong: The Cosmos.

Cheung, HN. 1972. A Grammar of Cantonese Spoken in Hong Kong. Hong Kong: The Chinese University Press.

Curriculum Development Council of Hong Kong SAR. 2006. Suggested Learning Objectives of Chinese Language in Secondary Schools (Trial Version). http://www.edb.gov.hk/FileManager/TC/Content_5805/nss_lo_chi_lang.pdf. Accessed 12 Jan 2010.

Delia Memorial School (Broadway). 2003. (Course Design for Chinese as a Second Language for Non-Chinese secondary students), QEF (Quality Education Fund) number: 2003/0223.

Education Bureau (EDB) of Hong Kong SAR. http://www.edb.gov.hk. Accessed: 10 Dec 2009.

Education Commission (EC). 1996. Education Commission Report no. 6. Hong Kong: Government Printer.

Education Commission (EC). 2005. Report on review of medium of instruction for secondary schools and secondary school places allocation. Hong Kong: Government Printer.

Education Commission (EC). http://www.e-c.edu.hk. Accessed: 16 Mar 2010.

Education Department. 1997. Medium-of-instruction guidance for secondary schools. Hong Kong: Government Printer.

Erbaugh Mary, S. 1995. Southern Chinese dialects as a medium for reconciliation within Greater China. Language in Society 24: 79-94.

Evans, S, R Jones, R Rusmin, and O Cheung. 1998. Three Languages: One Future. In Language in Hong Kong at Century's End, ed. Pennington MC. 391-415. Hong Kong University Press.

Evans, Stephen. 2009. The medium of instruction in Hong Kong revisited: policy and practice reformed Chinese and English streams. Research Papers in Education 24(3): 287-309.

Gao, YH, XC Su, and L Zhou. 1998. Language attitudes in Hong Kong, Beijing and Guangzhou before the Hong Kong handover. Foreign Language Teaching and Research 2: 21-28.

Goh, YS. 2009. Bilingual Education Policy in Singapore: Challenges and Opportunities. In Language Teaching in a Multilingual World: Challenges and Opportunities, ed. Ward Christopher. 171-190. Singapore: SEAMEO Regional Language Centre. 
Goh, YS. 2009. TCSL in a multi-lingual situation: A case study of TCSL in Singapore. Journal of Yunnan Normal University (Teaching and Research on Chinese as a Foreign Language) 7(2): 6-12.

Guo, Xi. 2004. Sociolinguistics in China. Hangzhou: University of Zhejiang.

Hong Kong Examinations and Assessment Authority (HKEAA).http://www.hkeaa.edu.hk. Accessed: 10 Dec 2009.

Hong Kong SAR Government. 1996. The Education Commission Report No.6. http://www.edb.gov.hk/FileManager/EN/ Content_689/ecr6_e_2.pdf.

Huang, GG. 1997. Opinion on 1997 handover and Hong Kong's language. Journal of Guangdong Institute for Nationalities 2 91.

Huang, XY. 2009. 9000 Expressions in Business Cantonese. Beijing: World Publishing Corporation.

Jia, YF. 2008. Mastering Cantonese Conversation in Three Months. Dalian: Dalian Polytechnic University.

Language Centre of Hong Kong Baptist University.http://lc.hkbu.edu.hk/course_chinese_c.php. Accessed: May 2010.

Language Centre of the Hong Kong University of Science and Technology.http://lc.ust.hk/ courses/ug_fl.html. Accessed in May 2010.

Language Situation in China Group. 2005. Report on the Language Situation in China 2005. Beijing: Commercial Press.

Lee, KS, and WM Leung. 2010. A Preliminary Survey on the Use of Spoken Languages in Hong Kong's Workplace. Chinese Language Studies 1: 97-110.

Legislative Council Panel on Education of Hong Kong SAR. 2001. Language Fund (for discussion), Paper No. CB(2)666/00-01 (04).

Li, DCS. 2009. Towards 'biliteracy and trilingualism' in Hong Kong (SAR): Problems, dilemmas and stakeholders' views. AlLA Review 22: 72-84.

Long, HZ. 1998. Hong Kong people's attitude towards Cantonese and Putonghua: a quantitative and qualitative study. Chinese Language 1: 66-73.

Long, HZ. 1999. Occupational background and the stratification of language attitudes. Foreign Language Teaching and Research 1: 56-63.

Ma, Yin. 1985. Questions and Answers About China's Nationalities. Beijing: World Press.

Mackerras, Colin. 2003. Ethnicity in Asia. New York: Routledge Curzon.

Matthews, Stephen, and Yip Virgnia. 1994. Cantonese Comprehensive Grammar. London: Routledge.

Ming Pao Daily. 1997. Publicity of mother tongue teaching can hardly change parents' minds. 3 May.

Ming Pao Daily. 1997. Hong Kong federation of education workers supports mother tonque teaching. 30 May.

Ng, DFP. 2007. Medium and learning in Chinese and English in Hong Kong Classrooms. Language Policy 6(1): 135-162.

Pasona Education of Hong Kong.http://www.pasona.edu.hk/tchi/for_students.html. Accessed: 1 May 2010.

Pennington, MC, and F Yue. 1994. English and Chinese in Hong Kong: Pre-1997 language attitudes. World Englishes 13(1): $1-20$.

Policy Address of Hong Kong SAR.http://www.policyaddress.gov.hk. Accessed: 4 Dec 2009.

Poon Anita, YK. 1999. Chinese medium instruction policy and its impact on English learning in post-1997 Hong Kong. International Journal of Bilingual Education and bilingualism 2(2): 131-146.

Poon Anita, YK. 2000. Medium of instruction in Hong Kong: Policy and Practice. Lanham, MD: University Press of America.

Poon Anita, YK. 2004. Language policy of Hong Kong: Its impact on language education and language use in post-handover Hong Kong. Journal of Taiwan Normal University: Humanities \& Sciences 49(1): 53-74.

Poon Anita, YK. 2010. Language use, and language policy and planning in Hong Kong. Current Issues in Language Planning 11: 1. 1-66.

Qi, GZ. 2004. A Report on the First Year and a Half of the Bilingual Education Experimental Class at Narisi Primary School, Dongxiang County. China.

Spack, Ruth. 2002. America's Second Tongue: American Indian Education and the Ownership of English, 1960-1900. Lincoln, NE: Univ. of Nebraska Press.

Spolsky, Bernard. 2004. Language Policy. Cambridge, UK; New York: Cambridge University.

Standing Committee on Language Education and Research. 2003. Action plan to raise language standards in Hong Kong. Hong Kong: SCOLAR, Education and Manpower Bureau.

Standing Committee on Language Education and Research (SCOLAR). 2003. Action Plan to Raise Language Standards in Hong Kong - Final Review Report. Hong Kong: Standing Committee on Language Education and Research.

Standing Committee on Language Education and Research (SCOLAR). 2008. Research summary of the factors contributing to the implementation of PMI in primary and secondary schools in Hong Kong. Hong Kong: Standing Committee on Language Education and Research.

Standing Committee on Language Education and Research (SCOLAR).http://www.language-education.com. Accessed: 10 Dec 2009

Literacy and Development: Ethnographic Perspectives. ed. Street B. London/New York: Routledge.

Teng, Xing. 2000. Cultural Change and Bilingual Education. Beijing: Jiaoyu kexue chubanshe.

The American Chamber of Commerce in Hong Kong (ACCHK). 2008. Business Outlook Survery. http://www.amcham.org.hk/ hongkong/business_outlook_survey2008/2008_Report_FINAL.pdf. Retrieved 1 March, 2011.

Tong Keith, ST, and James Gregory. 2007. Colloquial Cantonese. London, New York: Routledge.

Tse, SK, MSK Shum, WW Ki, and CPC Wong. 2001. The transition from English to mother-tongue Chinese as medium of instruction. Educational Studies in Language and Literature 1: 9-36.

Tsou Benjamin, K, and RJ You. 2007. A Course in Sociolinguistics. Taipei: Wunan Book Co., Ltd.

Tsui, ABM. 2007. Language Policy and the Social Construction of Identity: The Case of Hong Kong. In Language Policy, Culture, and Identity in Asian Contexts, ed. Tsui ABM, Tollefson JW. 121-141. Mahwah, NJ: Lawrence Erlbaum.

Wilkinson, JS, and C Lu. 2001. Putonghua-Language Radio Programming in Hong Kong: RTHK and the Putonghua Audience. Canadian Journal of Communication 26: 1.

Wright, Sue. 2004. Language policy and language planning: from nationalism to globalisation. Basingstoke, Hampshire; New York, N.Y.: Palgrave Macmillan,

$\mathrm{Xu}, \mathrm{XY}$. 2007. Language policy and community language: aspects of the sociolinguistic survey of the Hokkien community in Singapore. Beijing: Zhonghua Chubanshe. 
Yale-China Chinese Language Centre of the Chinese University of Hong Kong.http://www.cuhk.edu.hk/clc/ssp_series_2.pdf. Accessed: 1 May 2010.

Yip, Virgnia, and Matthews Stephen. 2006. Intermediate Cantonese. London, New York: Routledge.

Zhang, YH. 2011. A Comparative Study of Modern Practical Writing in Junior Secondary School Chinese Textbooks in Mainland China, Hong Kong and Taiwan. PhD Thesis. The University of Hong Kong.

Zheng, XR. 2002. Research on China's Ethnic Minority Language Teaching Materials Development for the Compulsory Education Years of Schooling. Beijing: Beijing Normal University manuscript; report to the Ford Foundation, Beijing.

doi:10.1186/10.1186/2191-5059-2-2

Cite this article as: Lee and Leung: The status of Cantonese in the education policy of Hong Kong. Multilingual Education 2012 2:2.

\section{Submit your manuscript to a SpringerOpen ${ }^{\circ}$} journal and benefit from:

- Convenient online submission

- Rigorous peer review

- Immediate publication on acceptance

- Open access: articles freely available online

- High visibility within the field

- Retaining the copyright to your article

Submit your next manuscript at $\boldsymbol{\nabla}$ springeropen.com 